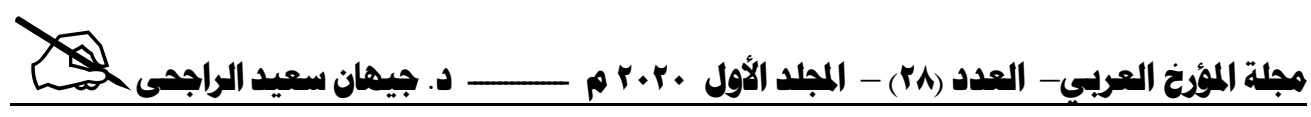

\title{
دور المرأة في ههنة السقاية عبر العصور التاريخية
}

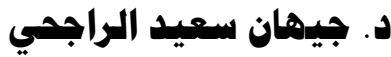

قسم العلوم الاجتماعية - كلية الآداب

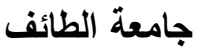

ملخص البحث:

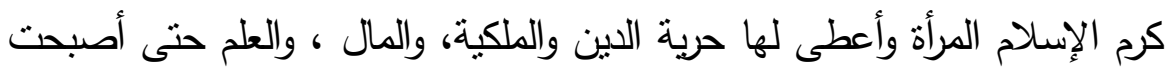

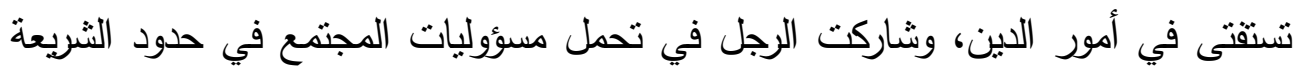

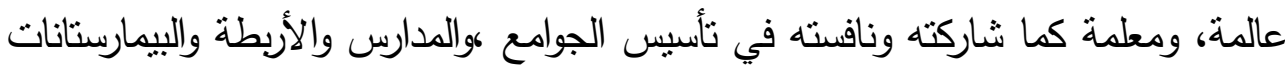

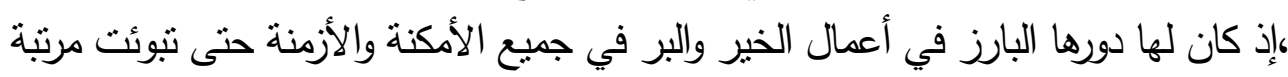

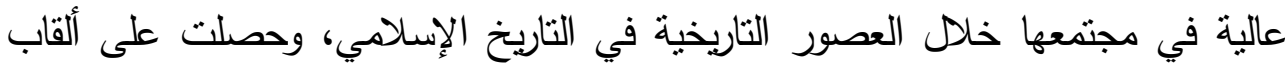

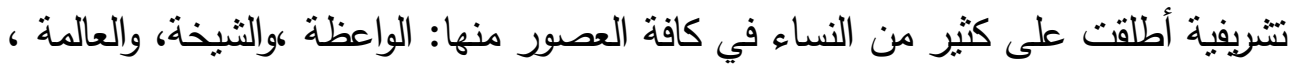
والفقيهة ، والصالحة، والمباركة والأصيلة ، والمحدثة ، والمسندة ، والخيرة الفئلة الفاضلة.

وهذه الدراسة محاولة لنقيم فكرة واضحة عن جانب من جوانب الدور الحضاري

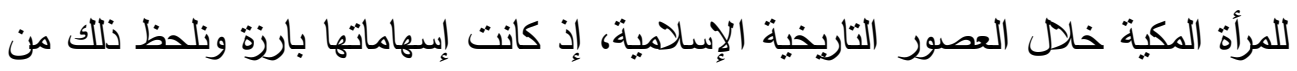

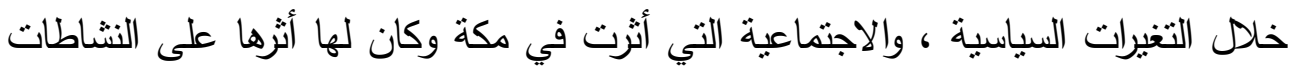

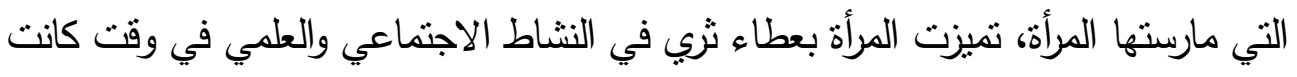

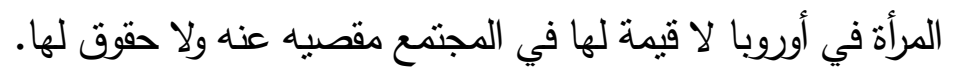

كما نتتاول الجانب الخيري والاجتماعي لدور المرأة في مهنة السقاية في كافة

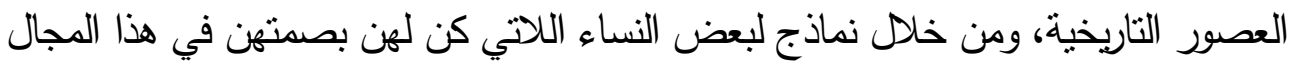

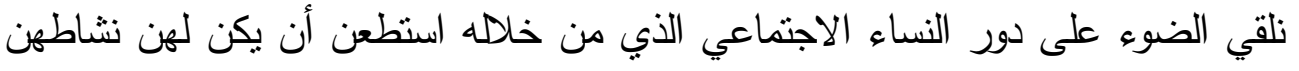

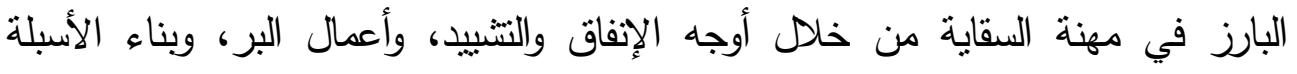

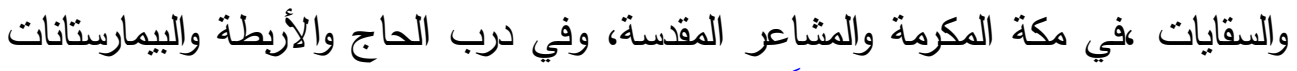
،وأعمال البر الأخرى إذ كن أنموذج لِنساء الحرمين ومشاركتهن الفعالة في المجتمع. 


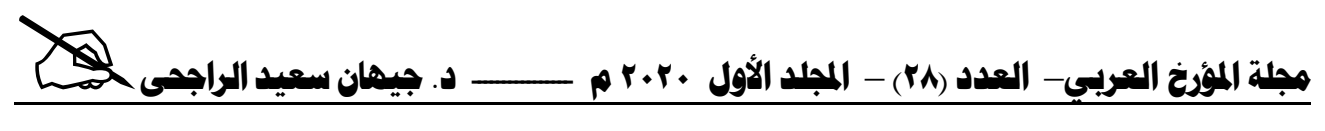

\section{Summary}

Islam honored the woman and gave her freedom of religion, property, money, and knowledge until she became a question in matters of religion, and the man participated in carrying out the responsibilities of society within the limits of the Sharia, a scholar and teacher, as it participated and compete with him in establishing mosques, schools, ligaments, and imams, as she had a prominent role in charitable work. Righteousness in all places and times until it assumed a high position in her society during the historical eras in Islamic history, and she obtained honorary titles given to many women of all ages, including: the preacher, the sheikh, the scholar, the jurist, the righteous, the blessed and the authentic, the modern, the musnad, and the good Virtuous.

This study is an attempt to provide a clear idea about one aspect of the civilizational role of the Meccan woman during the Islamic historical eras, as her contributions were prominent and we notice this through the political and social changes that affected Makkah and had an impact on the activities practiced by women. Social and scientific at a time when women in Europe had no value in society, excluded from it, and had no rights.

We also deal with the charitable and social aspect of the role of women in the watering profession in all historical eras, and through examples of some women who have had their mark in this field, we shed light on the social role of women through which they were able to have their prominent activity in the watering profession through aspects of spending and construction. , And the works of righteousness, and the building of basilicas and waterings, in Makkah Al-Mukarramah and the holy sites, and in the path of pilgrimage, ligaments, bimaristans, and other acts of righteousness as they were a model for the women of the Two Holy Mosques and their active participation in society. 


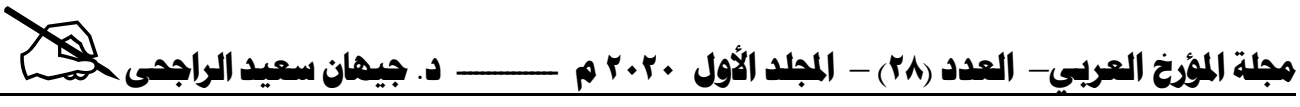

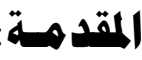

كرم الإسـالم المرأة وأعطى لها حرية الدين والملكية، والمال، والعلم حتى أصبحت

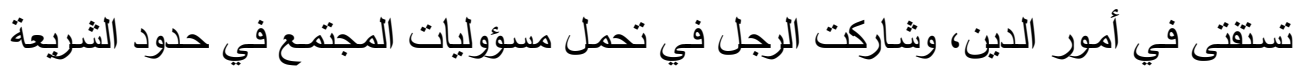

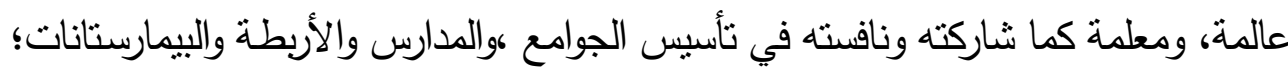

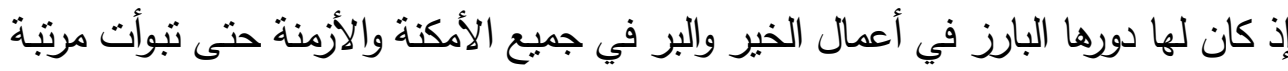

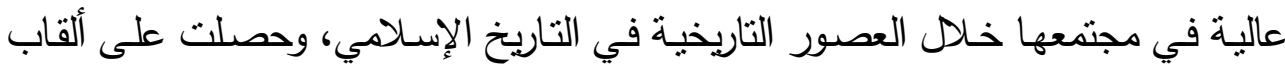

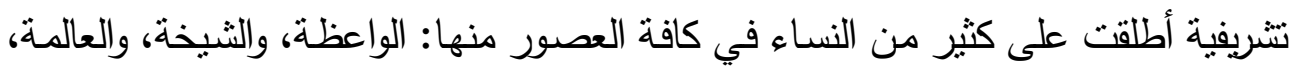

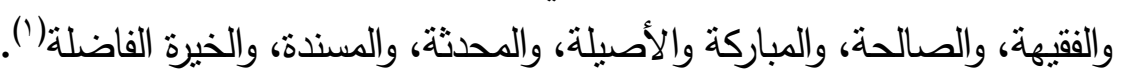

وهذه الدراسة محاولة لتقديم فكرة واضحة عن جانب من جوانب الدور الحضساري

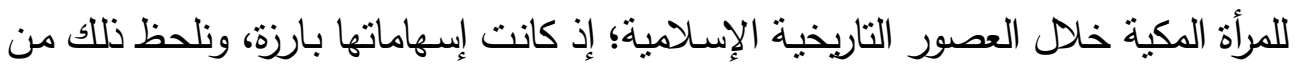

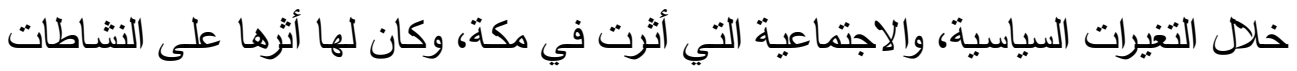

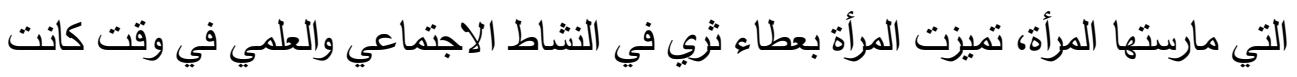

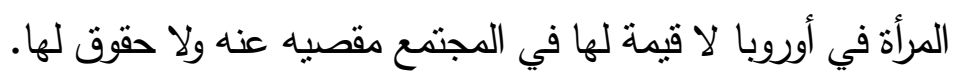
كما نتتاول الجانب الخيري والاجتماعي لدور المرأة في مهنة السقاية في كافة العصور

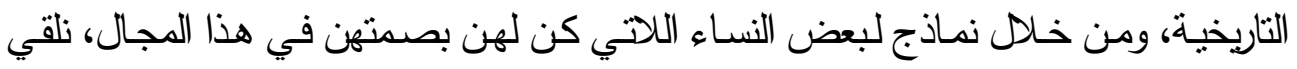

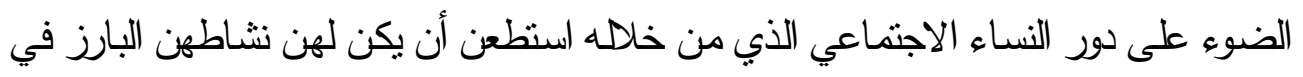

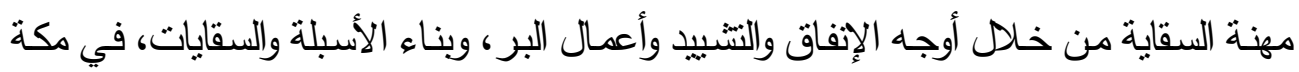

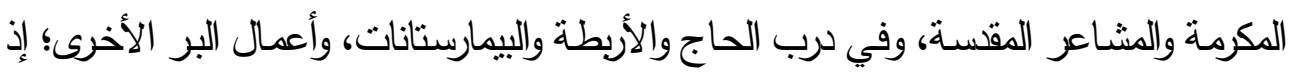
كن أنمونجًا لنساء الحرمين ومثاركتهن الفعالة في المجتمع.

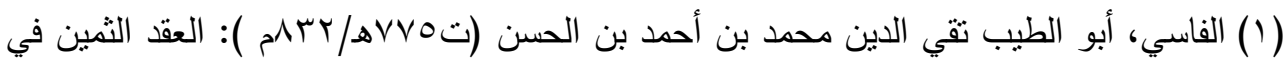

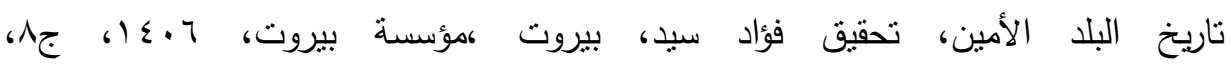

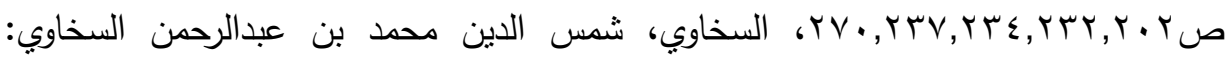

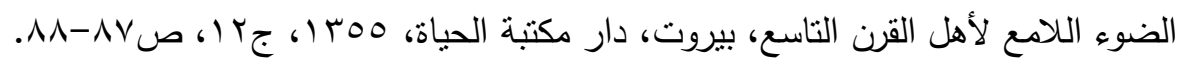




\section{دور المرأة في ههنة السقاية : المائ}

كانت السقاية من تلك القيم السامية التي عرفها العرب لماجرت عليه العادة في الجزيرة

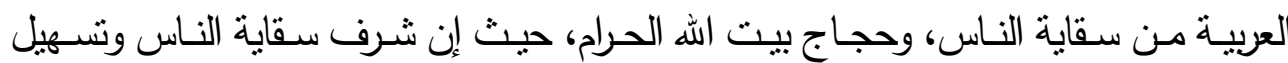

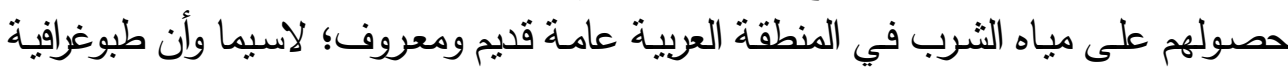

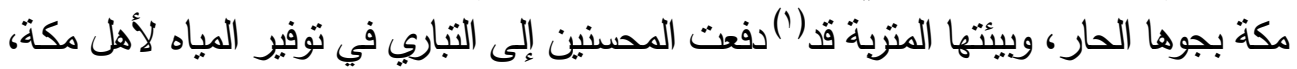

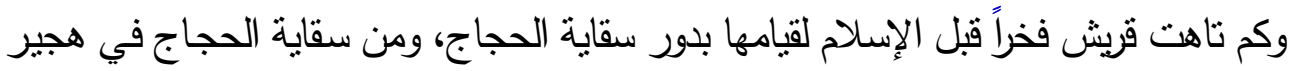

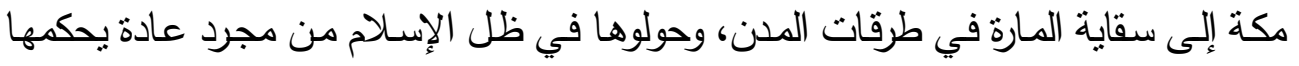

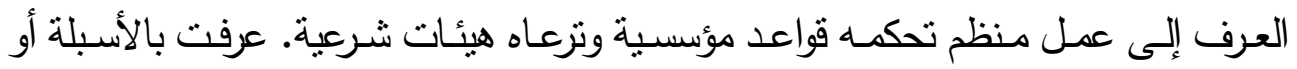

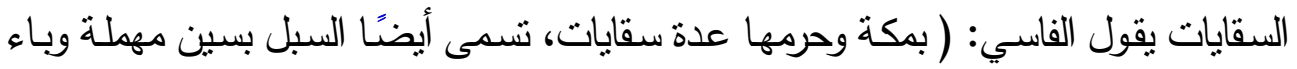

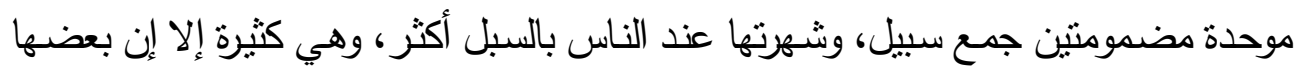
صار لا يعرف لخرابه وبعضها معروف مع معن الخراب).

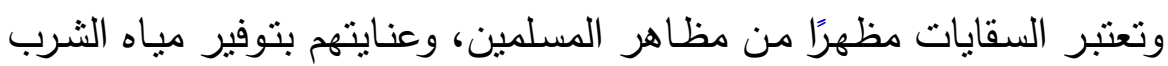

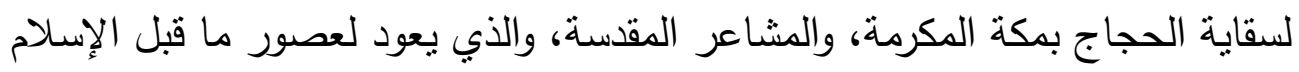

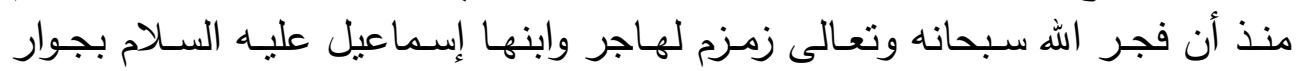

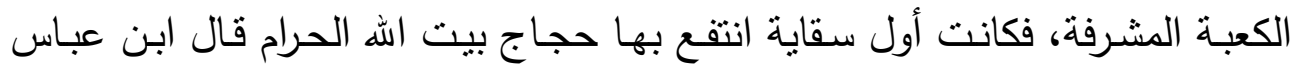

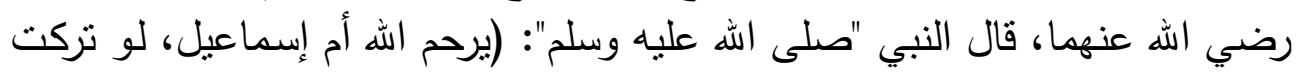

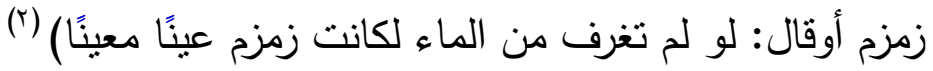

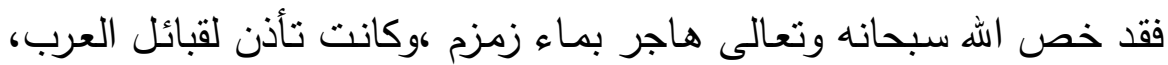

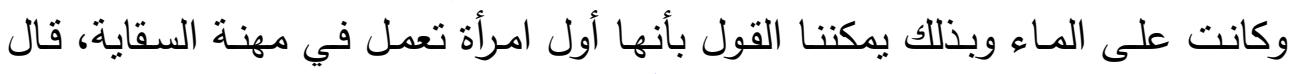

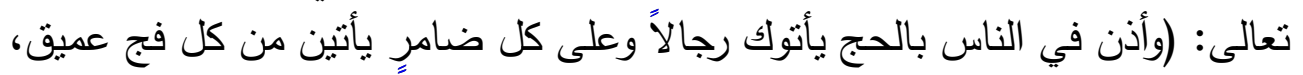

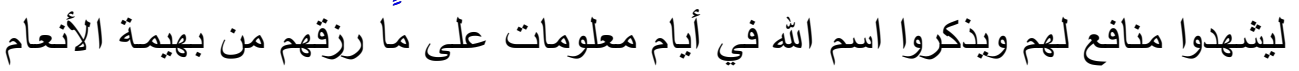

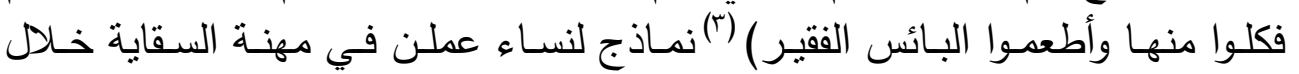

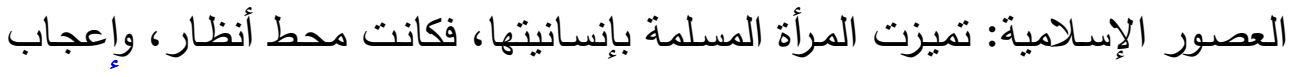

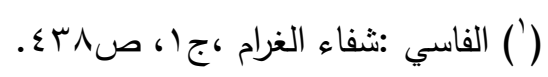

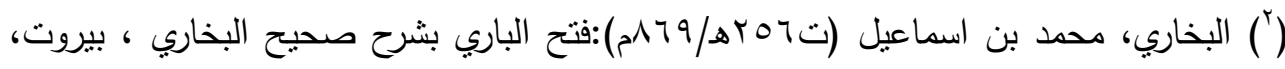

$$
\text { دار المعرفة (د.ت) }
$$

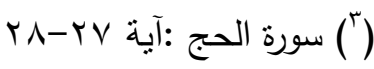


2

الدارسين والباحثين من الثرق والغرب، حتى إنه بمكننا القول بأن المرأة المسلمة كانت

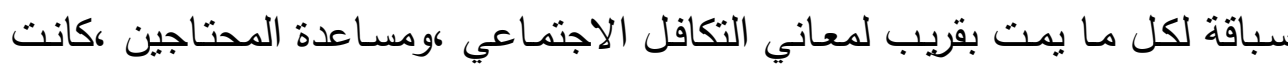

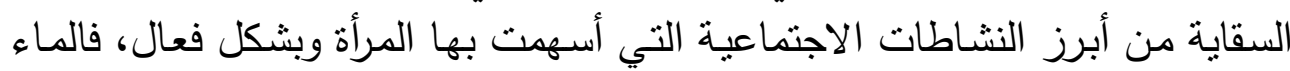

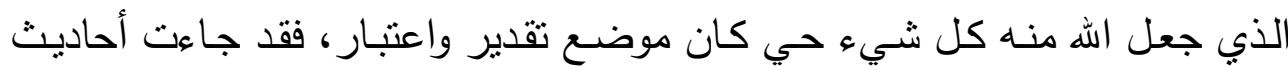

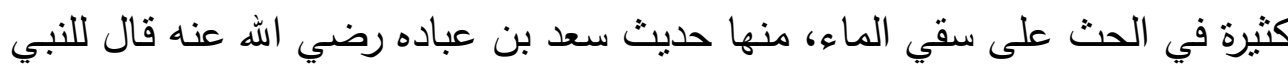

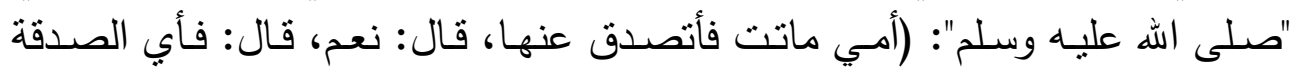

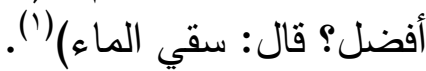

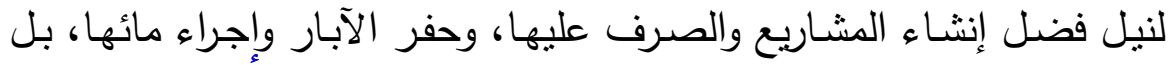

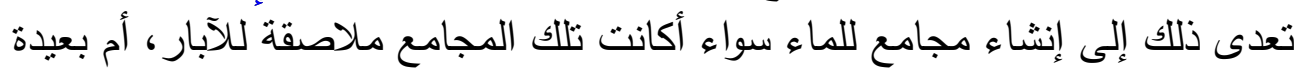

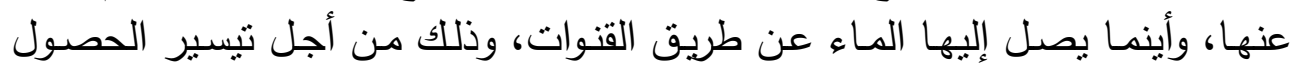

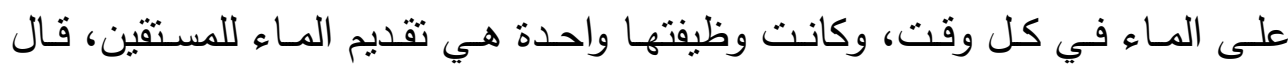

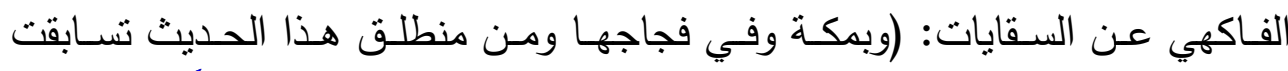

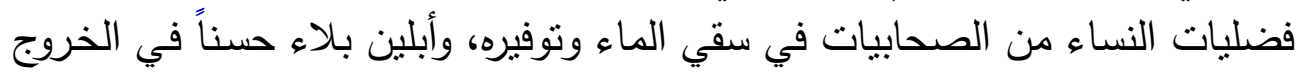

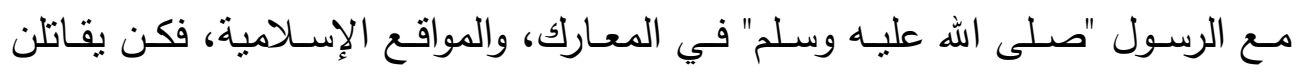

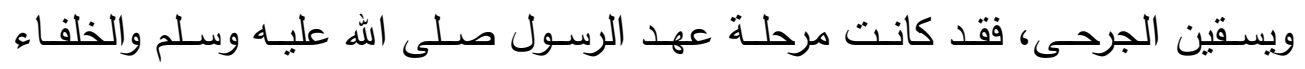

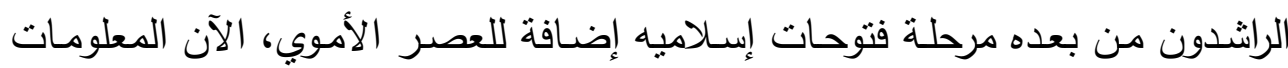

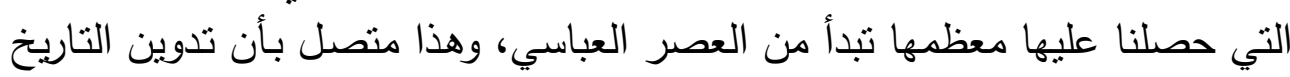

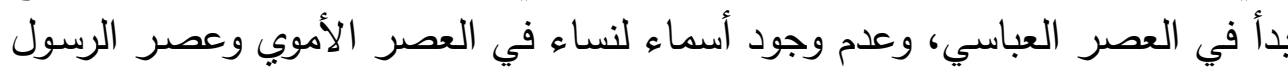

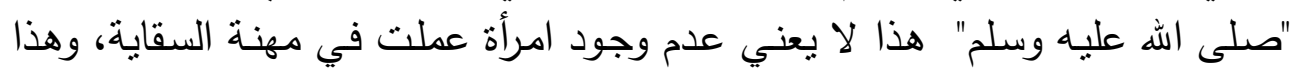

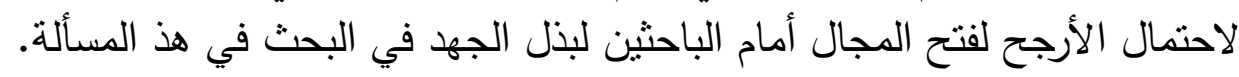

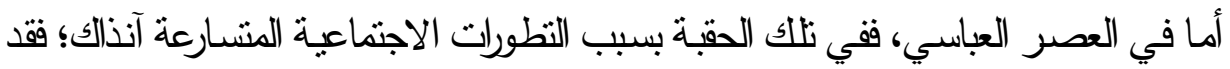

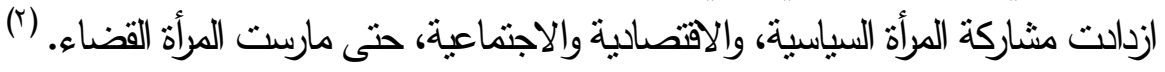

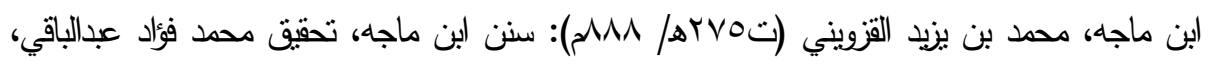

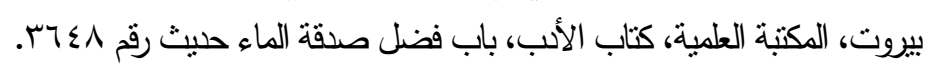

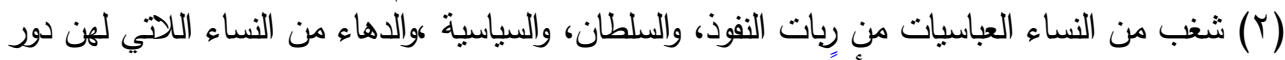

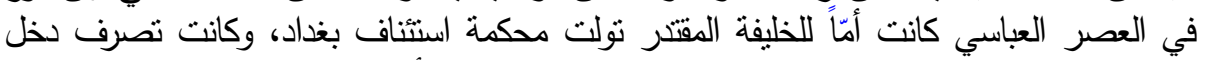

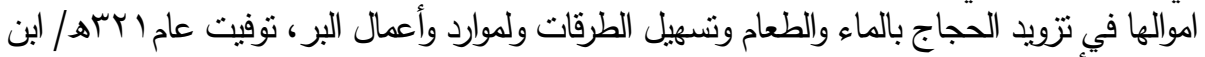

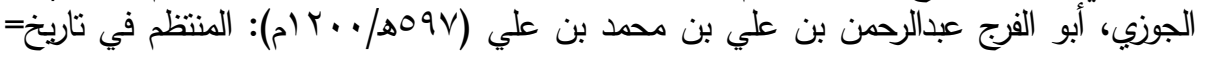




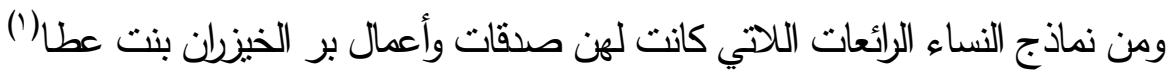

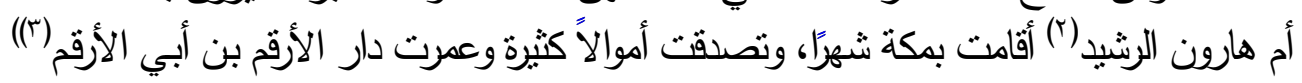

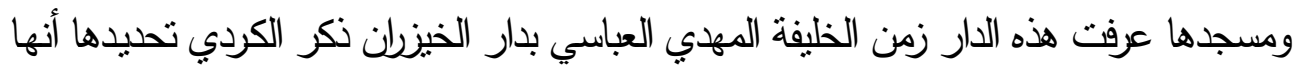

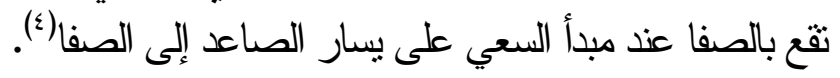

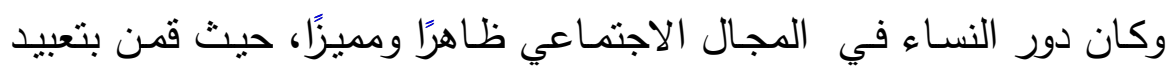

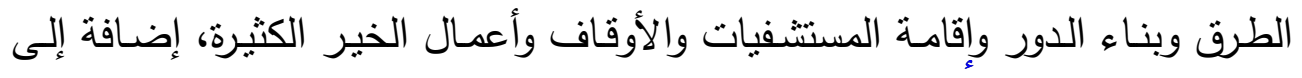

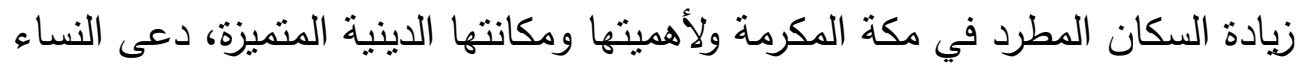

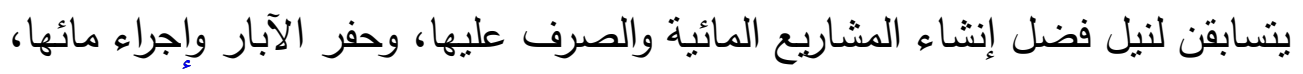

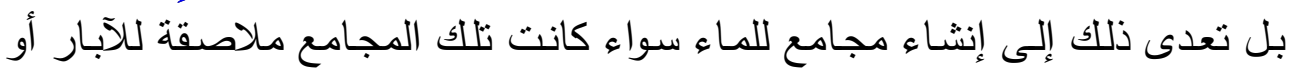

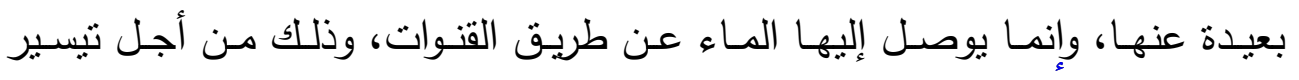

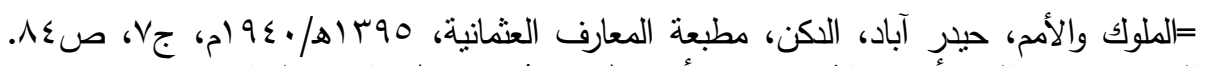

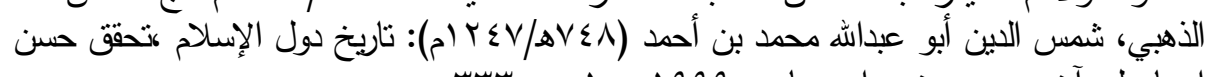

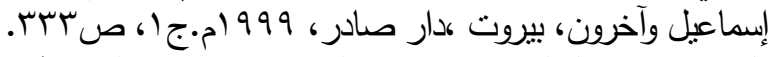

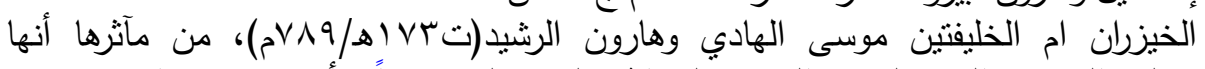

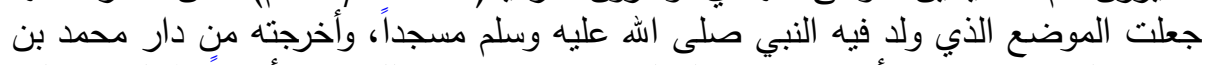

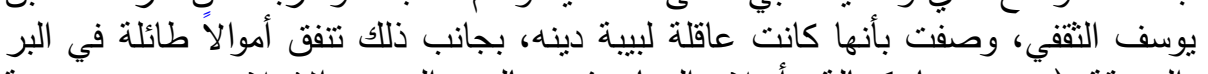

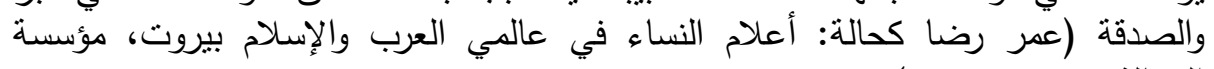

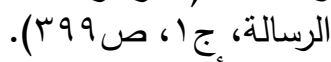

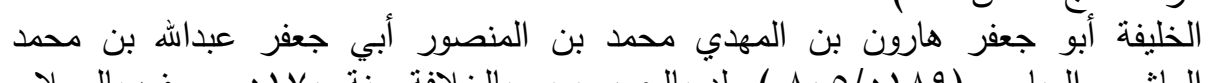

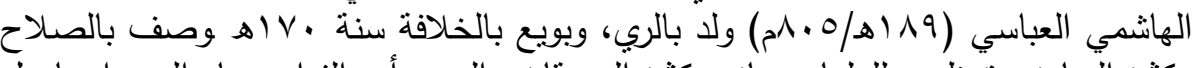

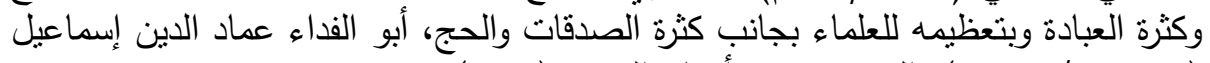

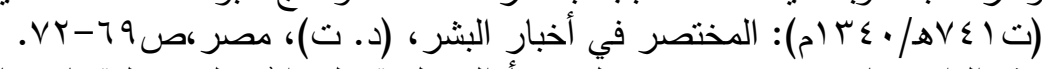

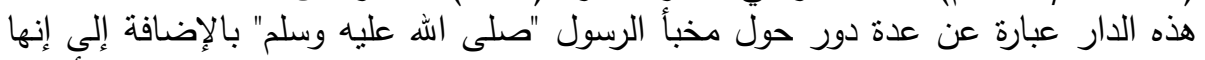

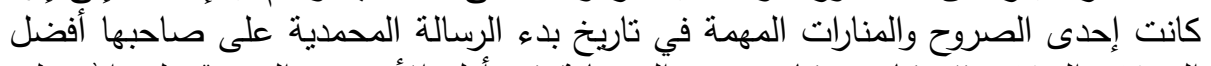

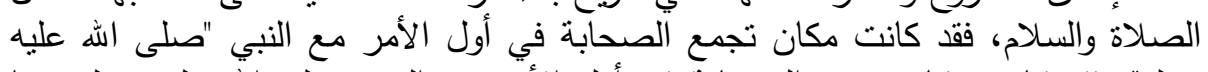

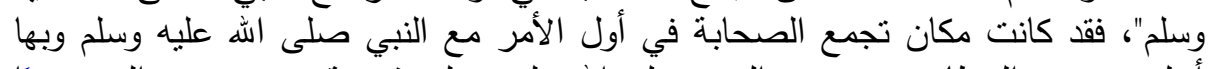

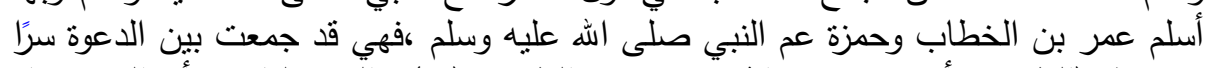

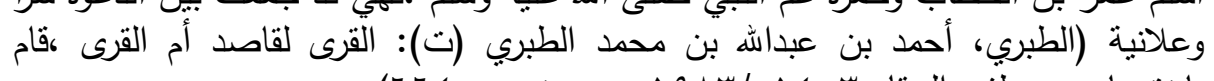

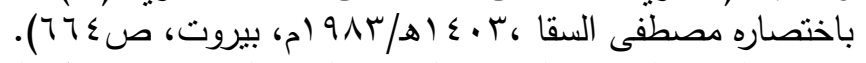

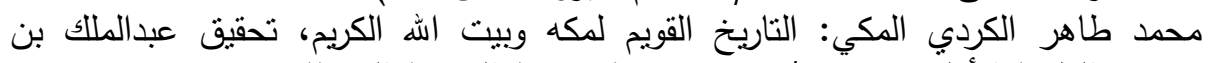

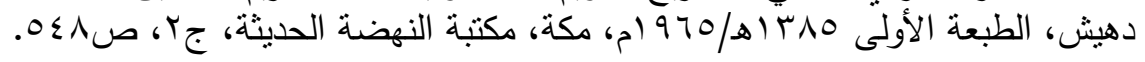




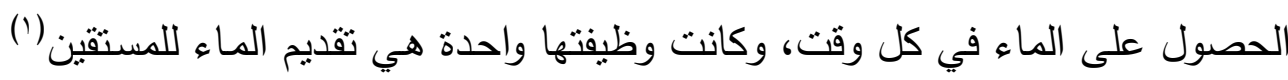

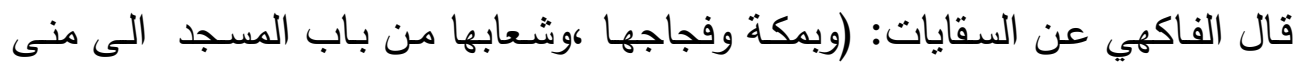

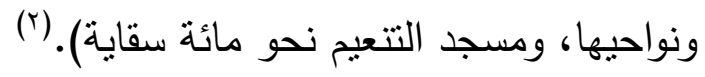

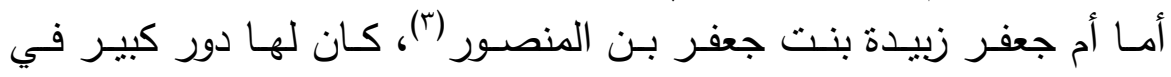

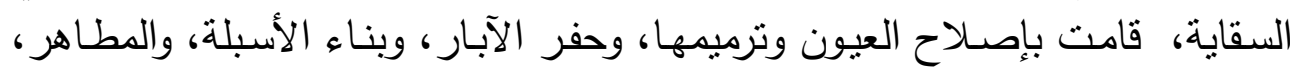

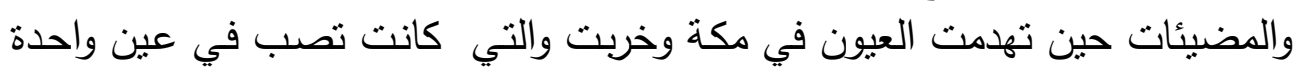

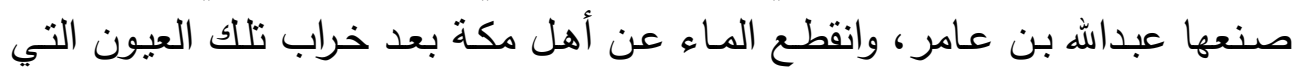

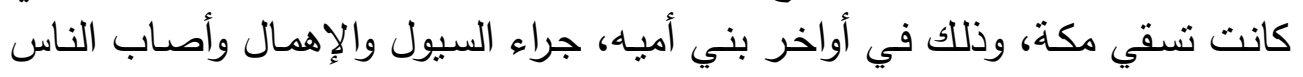

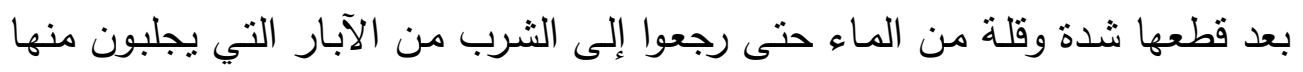

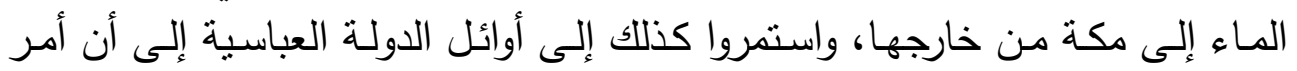

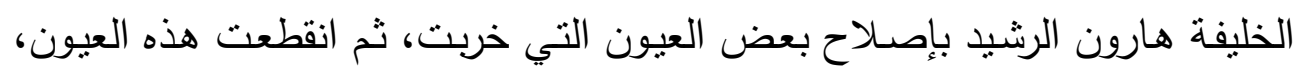

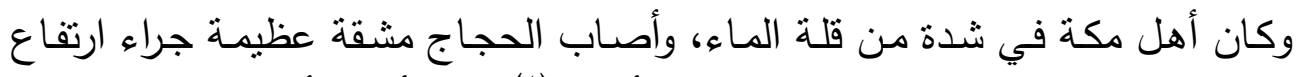

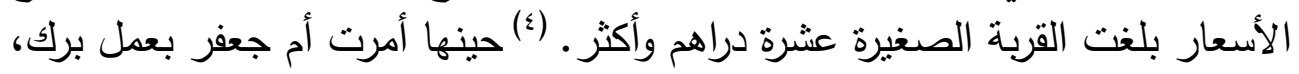

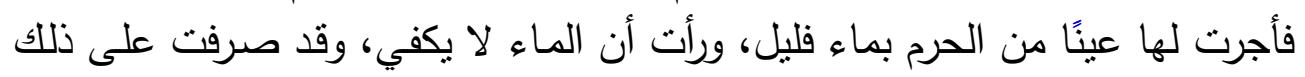

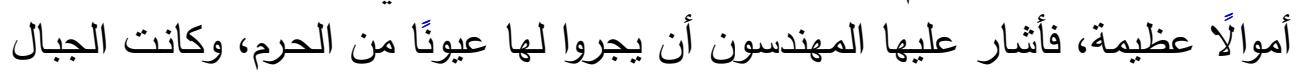

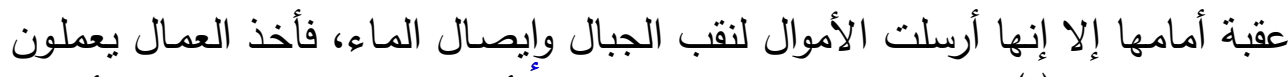

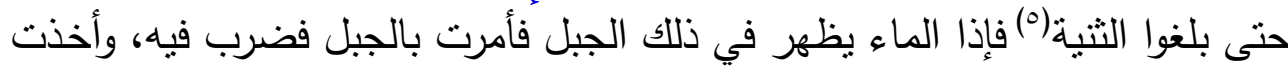

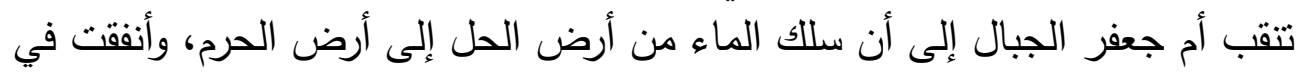

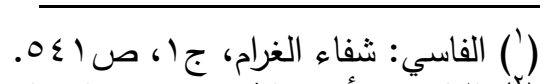

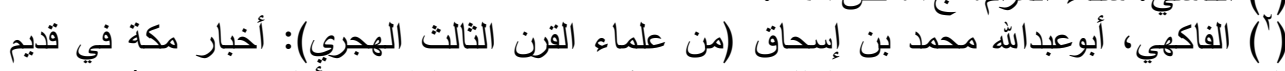

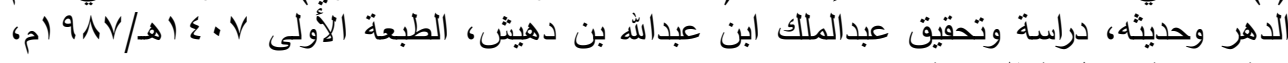

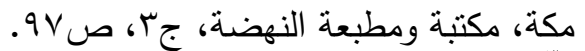

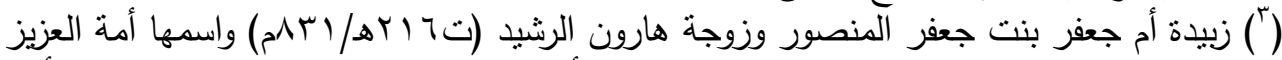

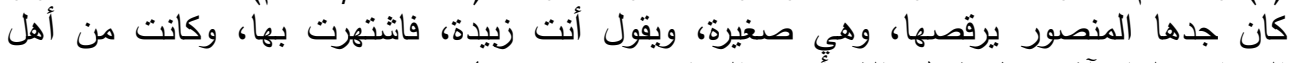

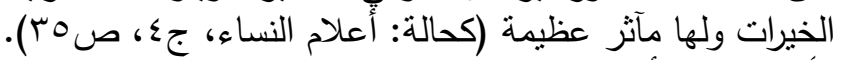

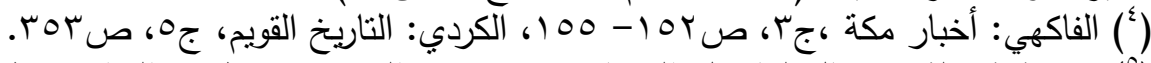

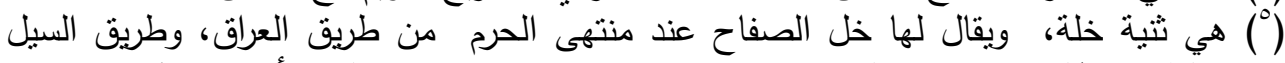

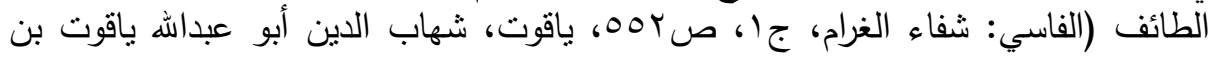

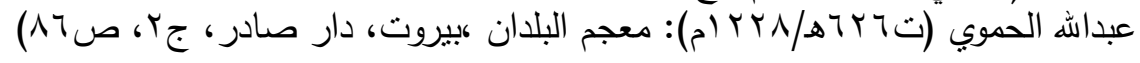




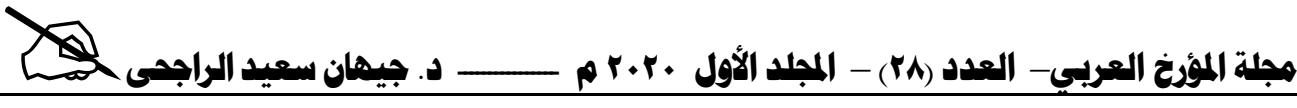

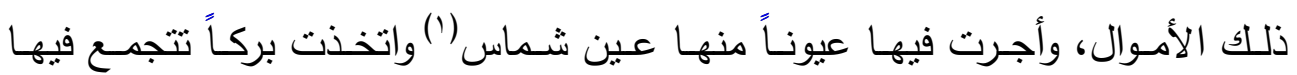

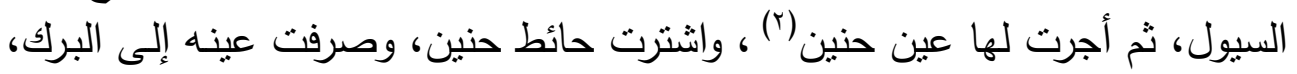

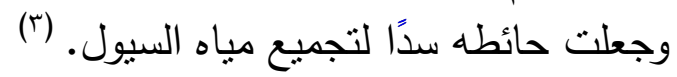

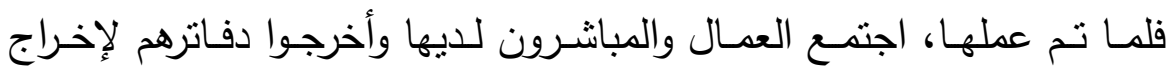

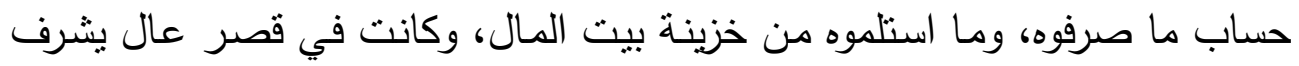

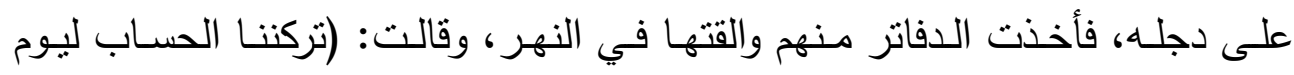

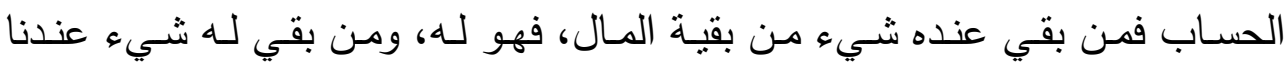

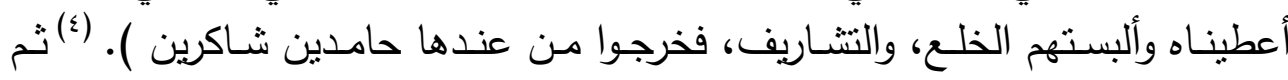

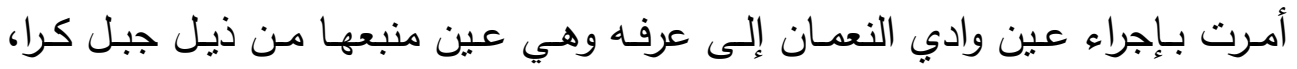

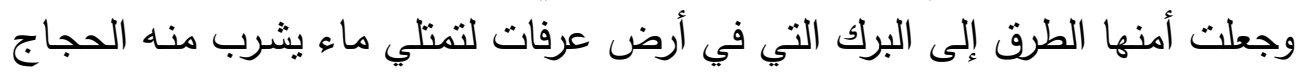

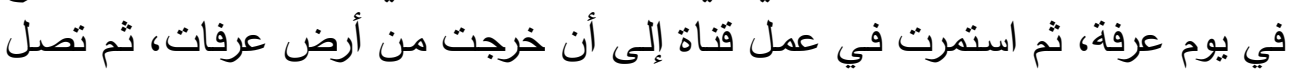

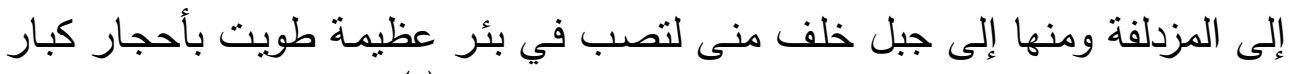

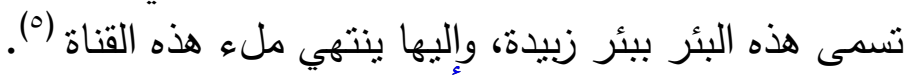

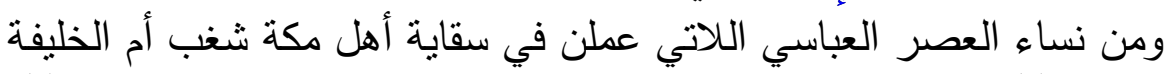

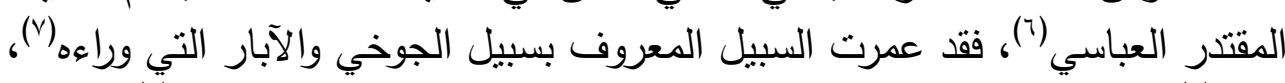

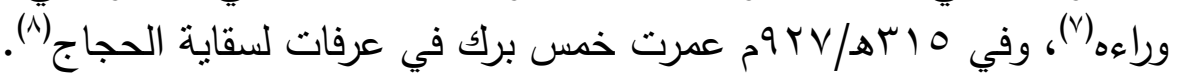

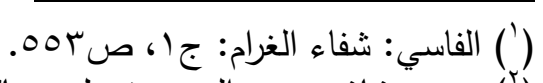

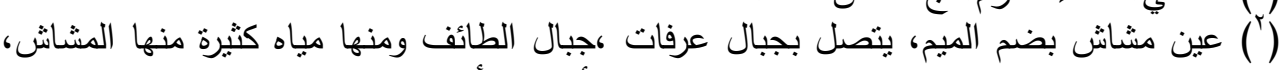

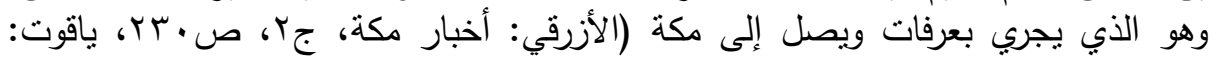

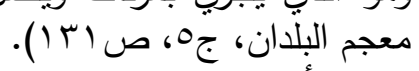

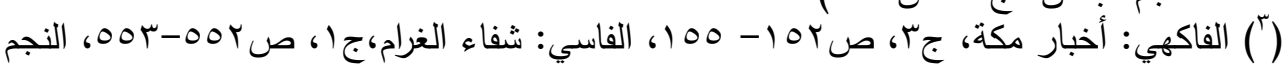

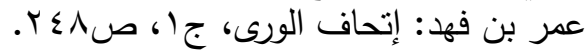

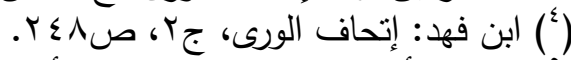

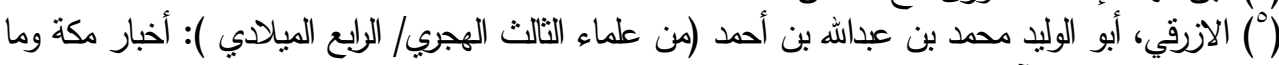

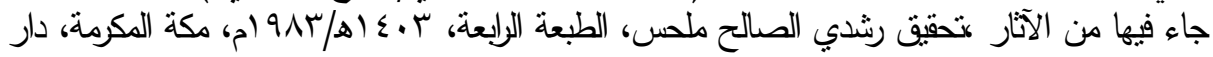

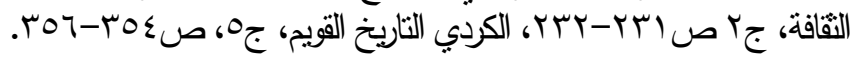

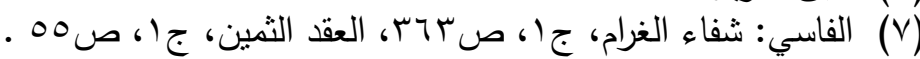

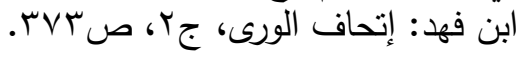


ومن عرفت بمبراتها الكثيرة وصدقاتها الوافرة في أرض الحرمين بنت ناصر الدولة

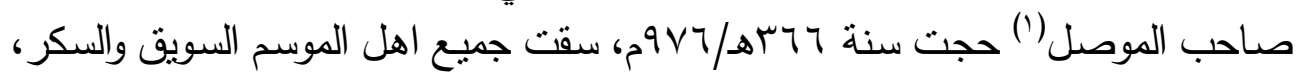

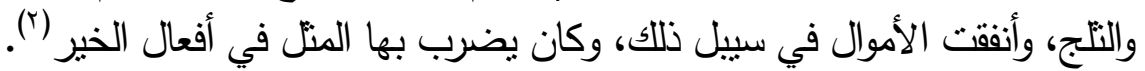

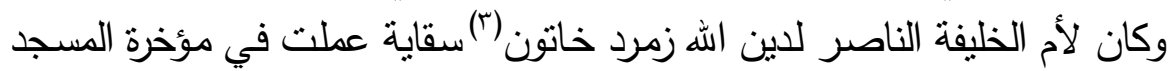

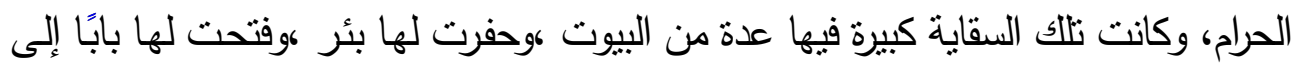

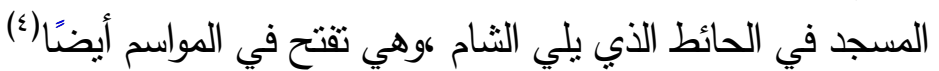

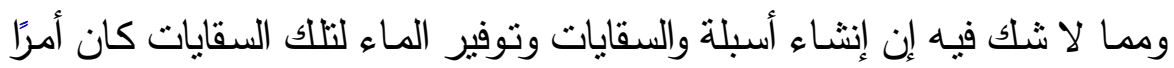

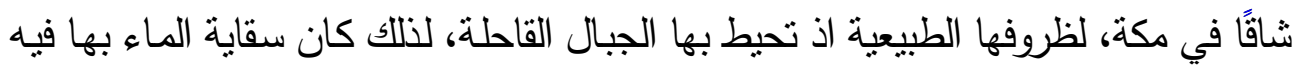

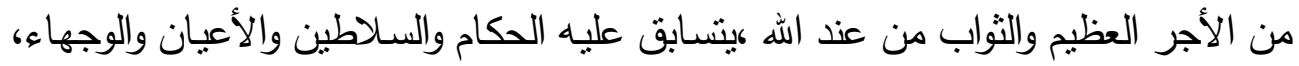

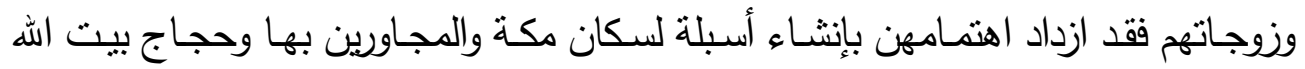

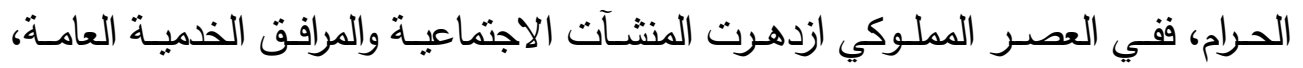

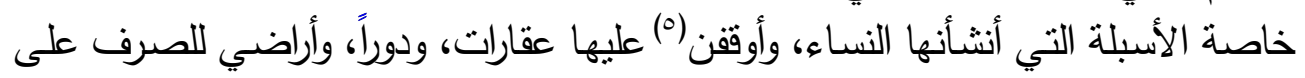

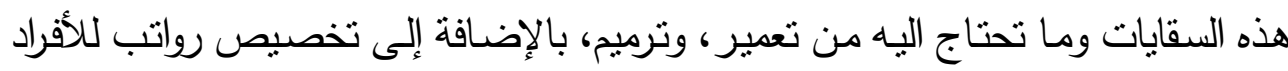

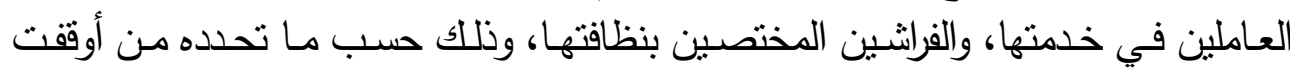

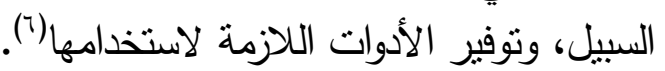

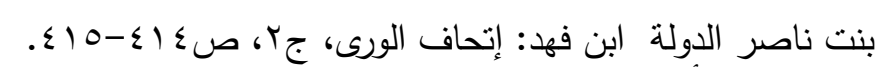

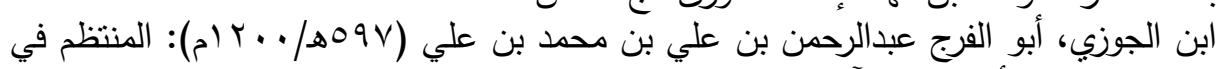

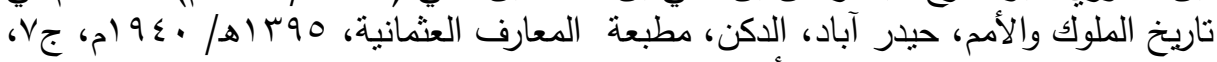

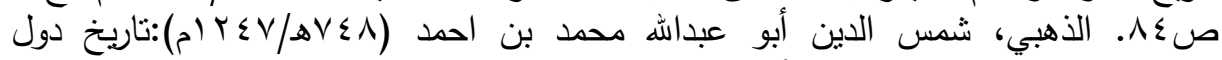

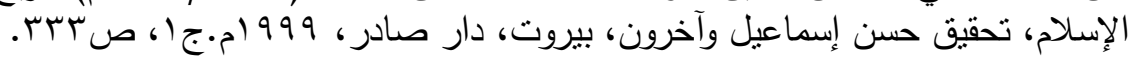

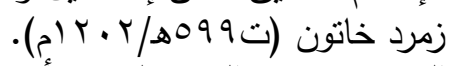

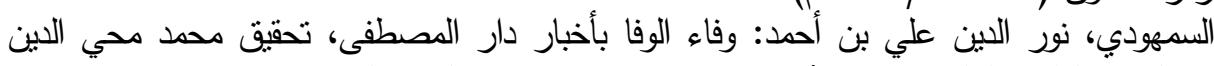

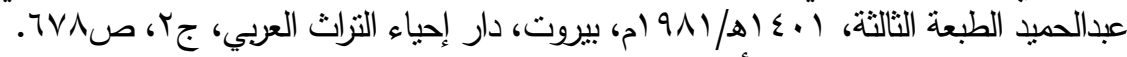

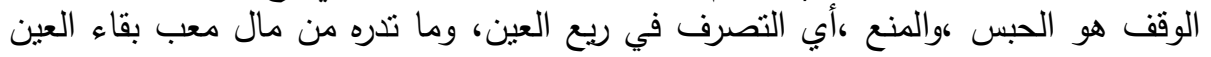

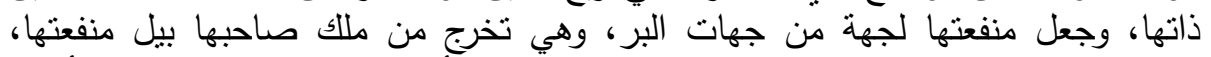

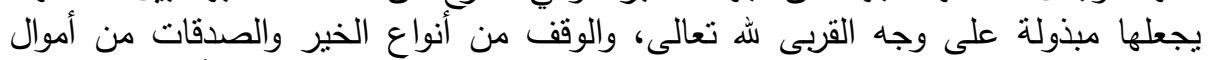

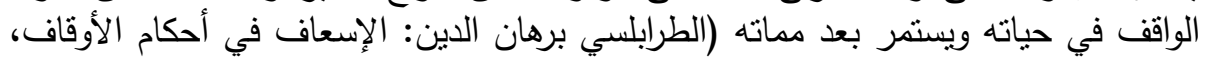

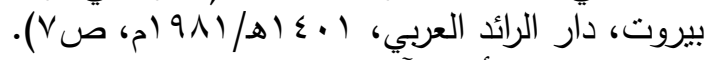

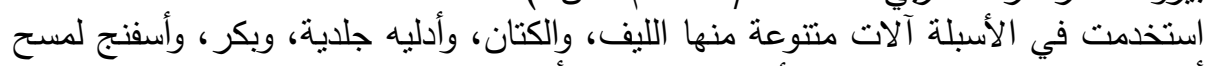

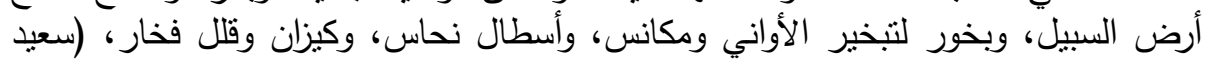
عاشور : المجنمع المصري عصر المماليك.ص (9) (9). 


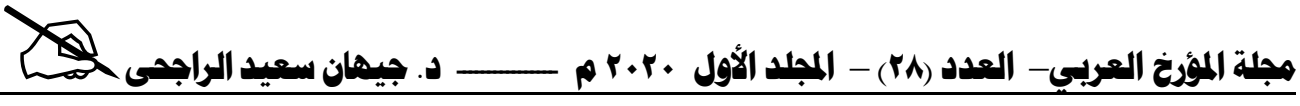

ومن نماذج النساء في العصر المملوكي نذكر منهن زهراء بنت محمد بن قلاون (')

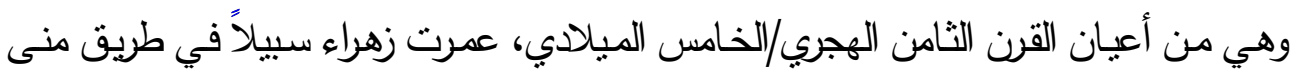

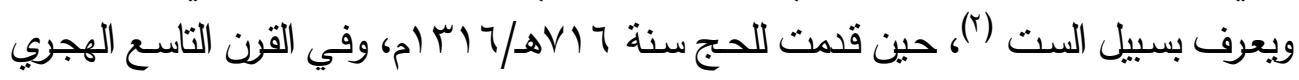
/الساس عشر الميلادي عرف بسبيل ابن مزنه(ب) .

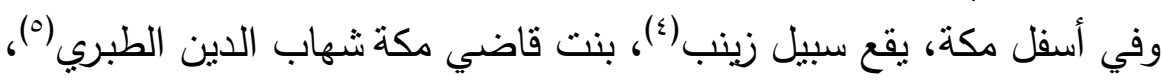

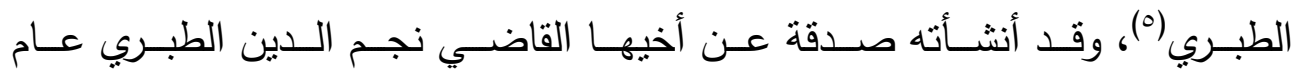
(T) ومن لهن السبق في أعمال البر والصدقات في العصر المملوكي أم الحسين بنت

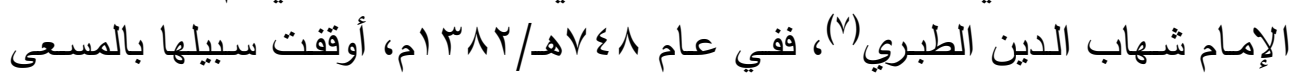
على يمين الذاهب إلى المروة عند موضع الجزارين، والخرازين، وقد ظل هذا السبيل

الفاسي: الزهور المقتطفة ،صو9419، ابن الضياء :تاريخ مكة المشرفة، ص90. 90.

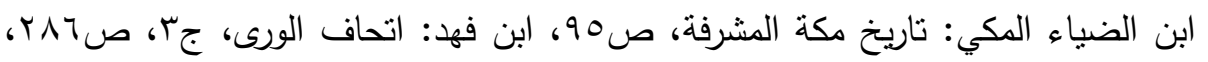

$$
\text { ولم نعرف لابن مزنه تعريف. }
$$

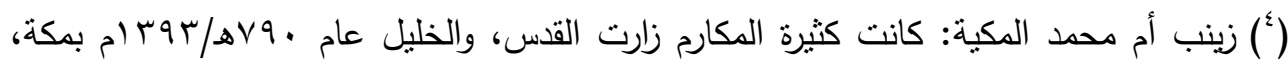

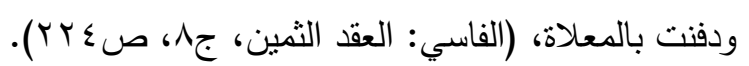

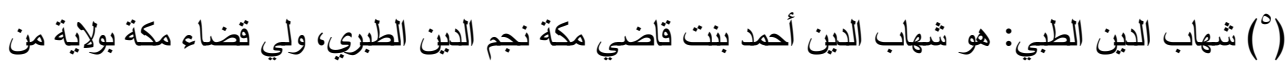

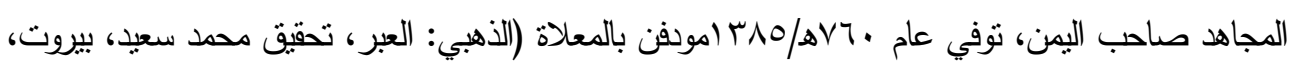

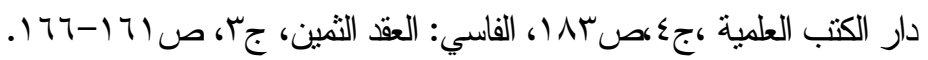

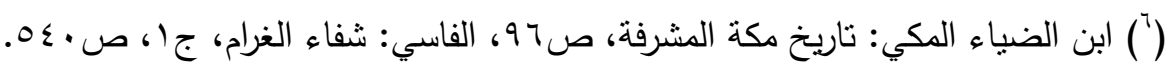

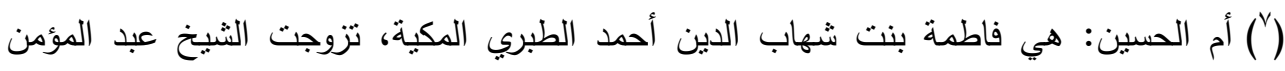

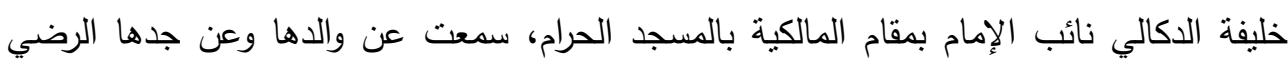

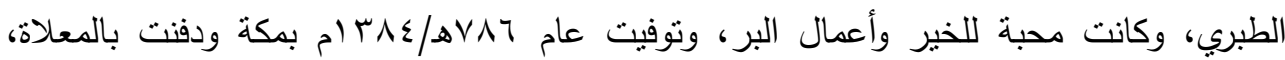

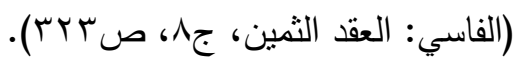




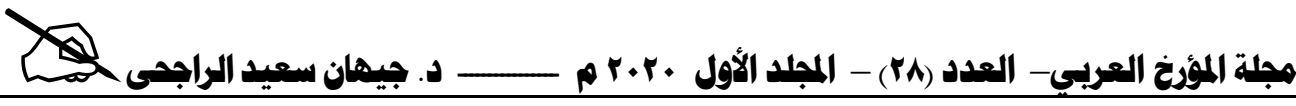

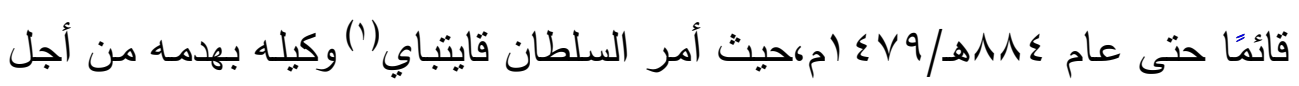

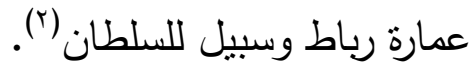

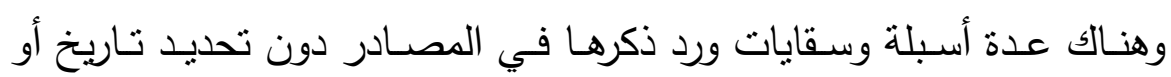

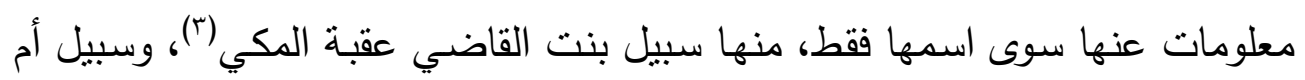

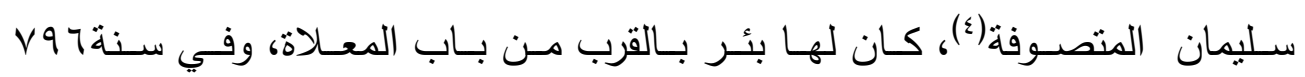

هـ/ به ام، عمرت مطهرة للنساء بسوق اليل (0). تعتبر السقايات والأسبلة التي أنشأت من قبل نساء من لن أبرز النماذج الني

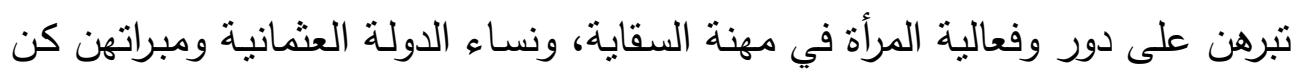

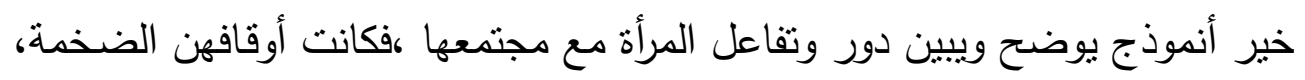

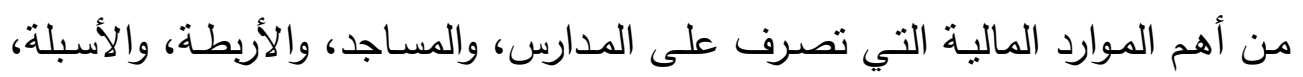

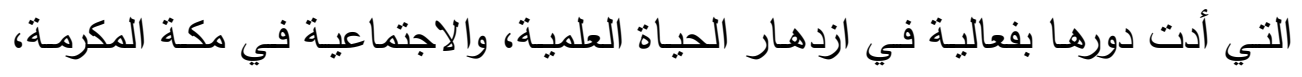
والمدينة المنورة، في تلك المرحلة.

فكن نساء القصر ، وزوجات السلاطين وبناتهم، ينسابقن في أعمال الخير من سن السابعة حتى السبعين من أعمارهن حتى أصبحن في مقاءة مؤسسي الوقف في التاريخ العثماني (؟) .

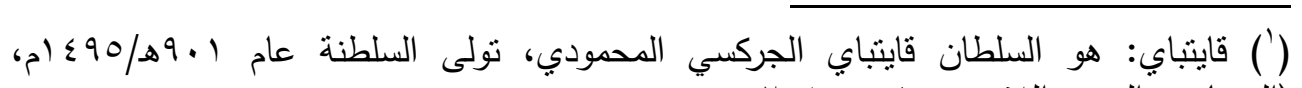

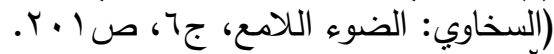

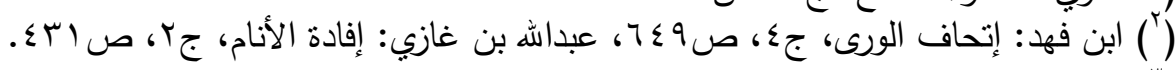

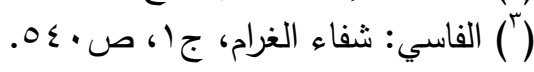

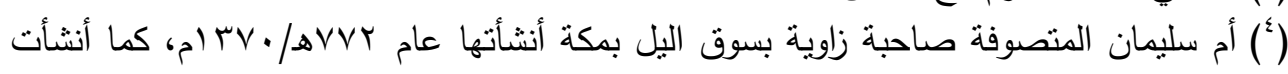

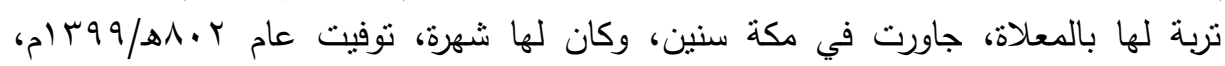

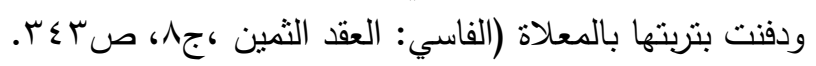

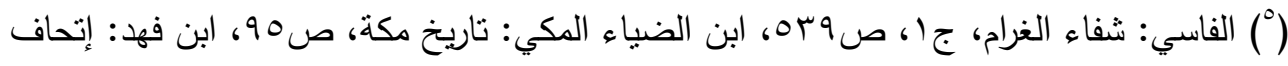

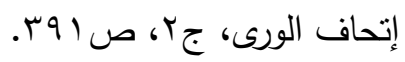

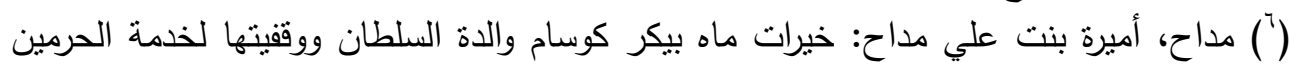

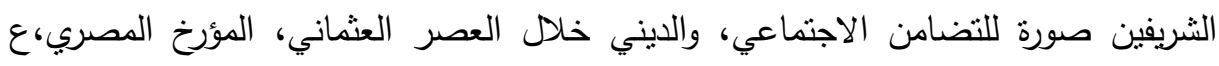




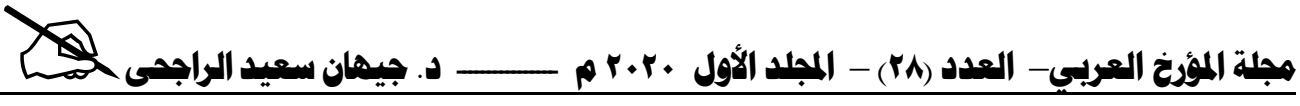

ومن نساء العصر العثماني اللاتي كن لهن دور بارز في مهنة السقاية، وأوقفن أوقافاً للحرمين الثريفين كانت زوجة السلطان أحمد الأول ماه بيكر كوسم سلطان ('أوققت أوقافاً لتوفير الماء في طريق الحجاج، وتوفير الإبل اللزمة لنقل تلك المياه(؟).

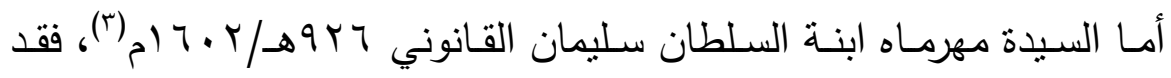

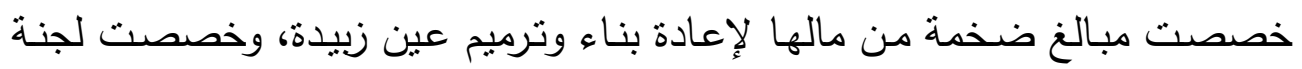

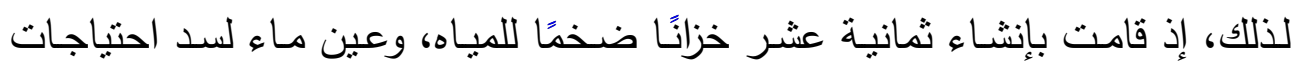

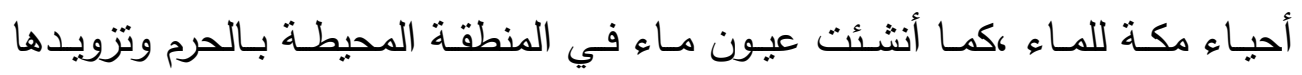
بالصنابير ، ليتوضأ الحجاج، إضافة لإيصالها للمياه إلى مسنتفى الفقراء والمؤسسات

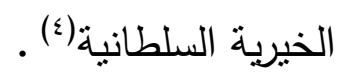

ومن نساء العصر العثماني اللاتي أوقفن المال لتوفير المياه وسقاية الحجيج

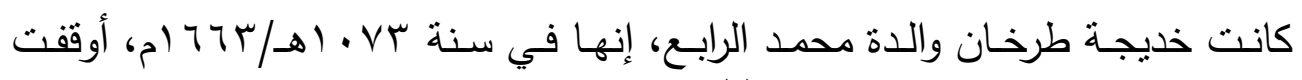

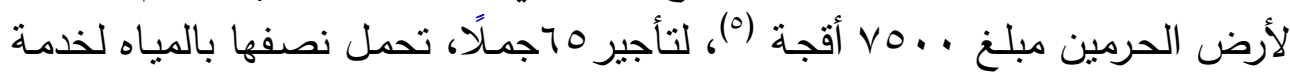

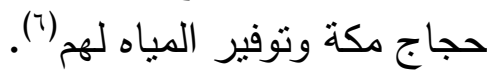

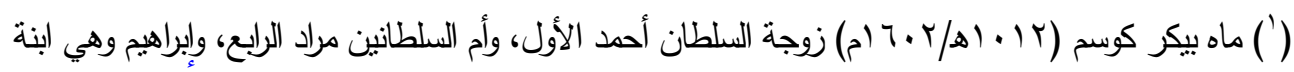

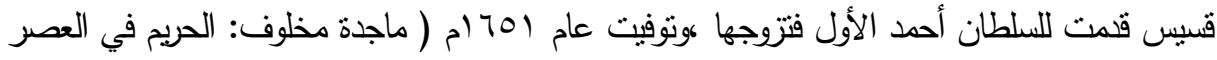

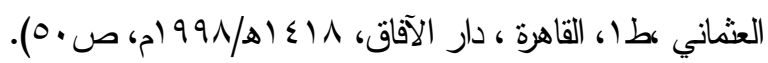

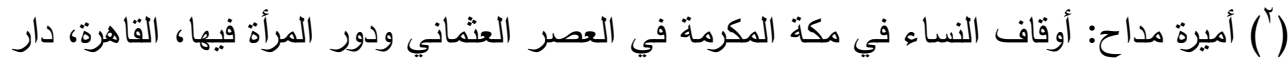

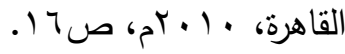

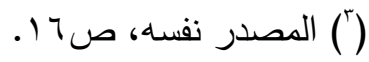
(4) ماجدة مخلوف: الخدمات والمرافق العامة في مكة المكرمة في العهد العثماني، مؤتمر مكة

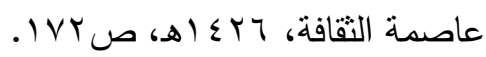

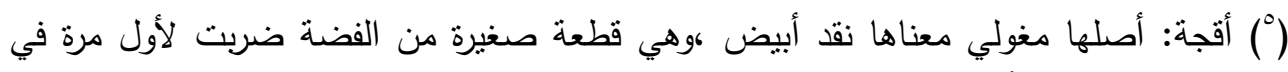

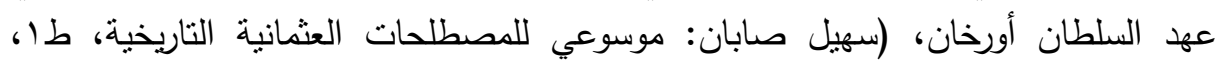

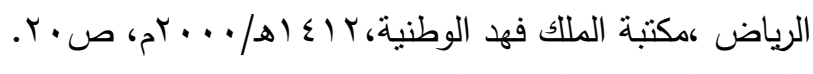

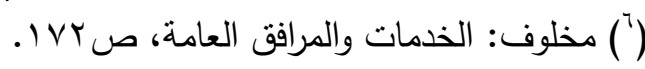




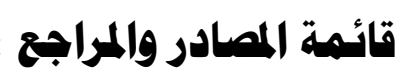

\section{المصادر المطبوعة:}

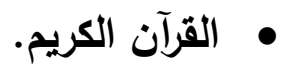

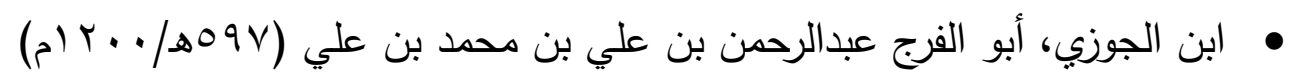

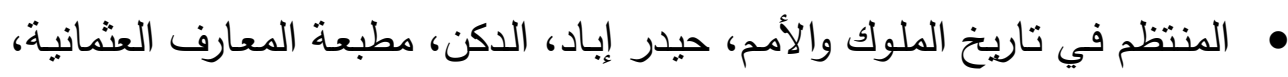

$$
\text { المن } 90
$$

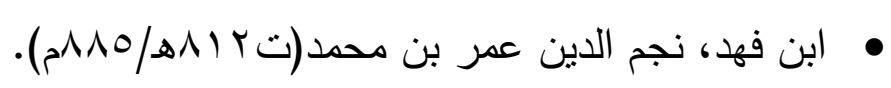

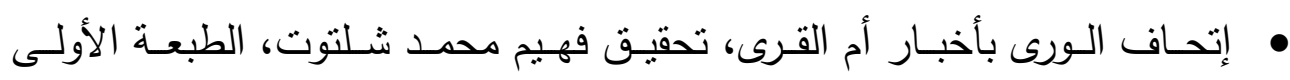

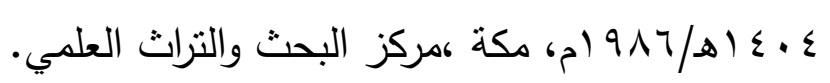

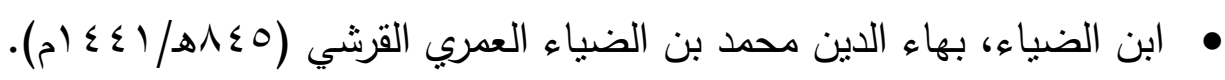

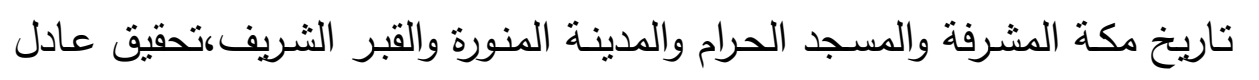

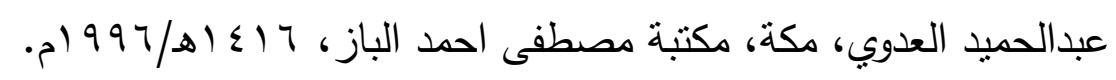

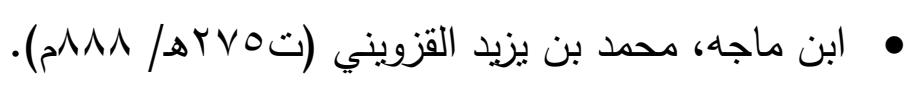

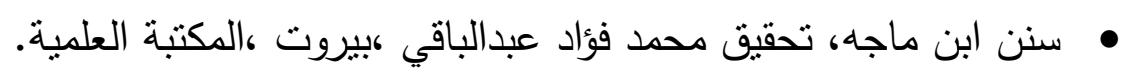

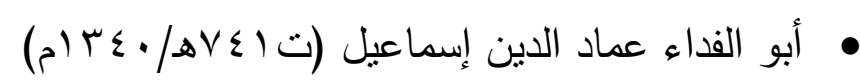

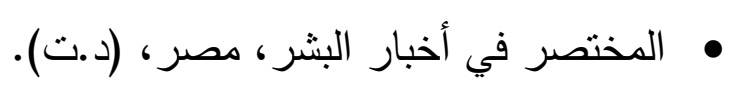

• • الأزرقي، أبو الوليد محمد بن عبداله بن أحمد (من علماء الثالث الهجري/ الهربع الديلادي).

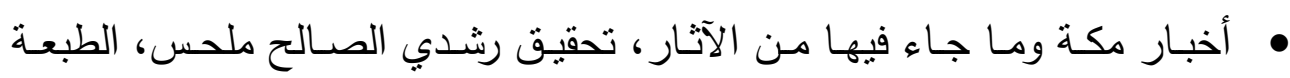

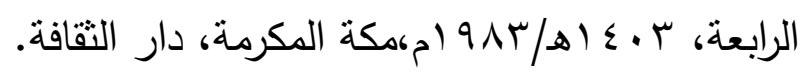

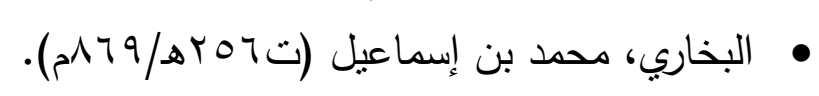

• فتح الباري بشرح صحيح البخاري، بيروت، دار المعرفة (د.ت). 


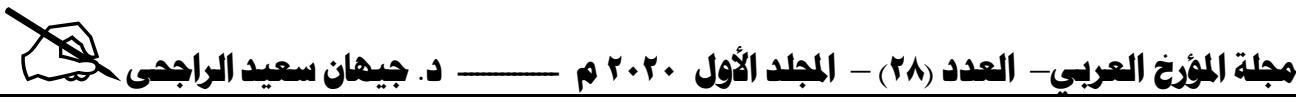

$$
\text { • السخاوي ،محمد بن عبدالرحمن السخاوي (r ـ9 هـ/ } 97 \text { (م). }
$$

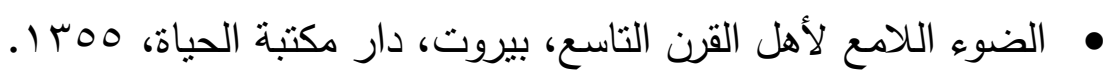

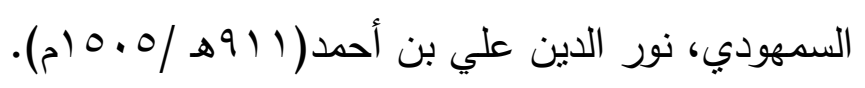

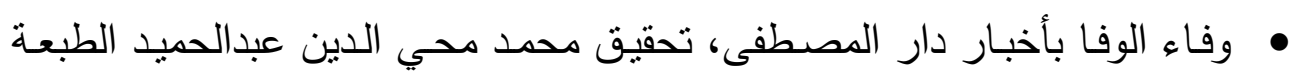

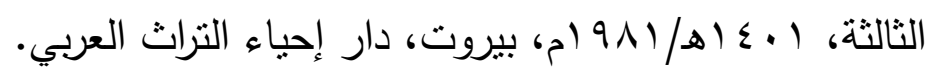

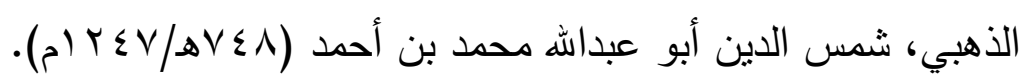

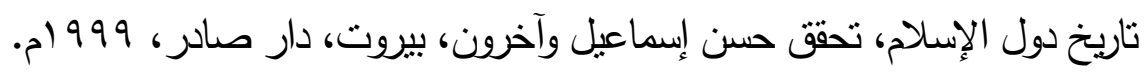
العبر ، تحقيق محمد سعيد ،بيروت ،دار الكتب العلمية.

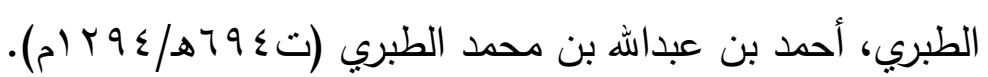

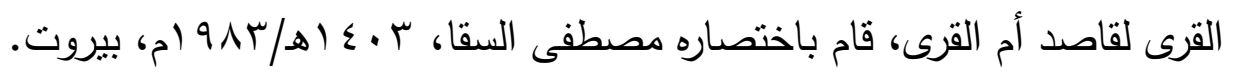

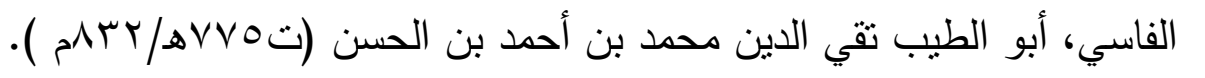
ه شفاء الغرام بأخبار البلد الحرام، تحقيق مجموعة من كبار العلماء والأدباء، مكة، مكتبة الباز .

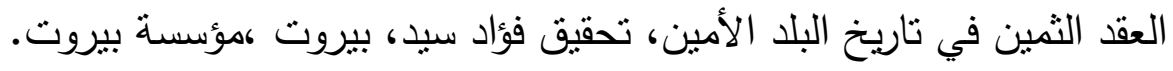
الزهور المقتطفة من تاريخ مكة المشرفة، تحقيق علي عمر، مكتبة الثقافة الدينية،

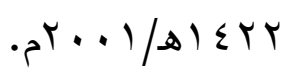

• الفاكهي، أبوعبداله محمد بن إسحاق (من علماء القرن الثالث الهجري).

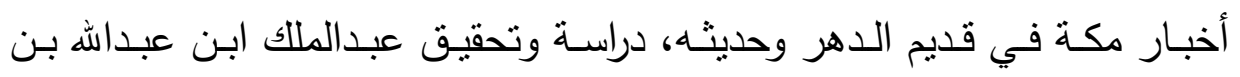

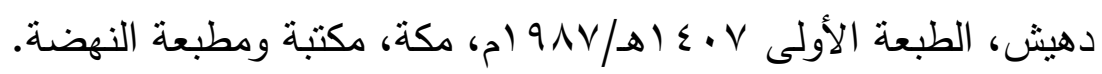

$$
\text { • الكردي، محمد طاهر الكردي المكي. }
$$

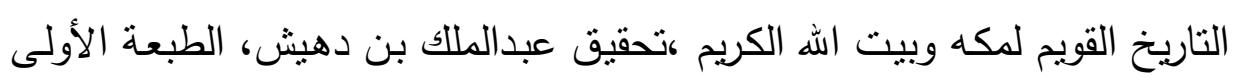

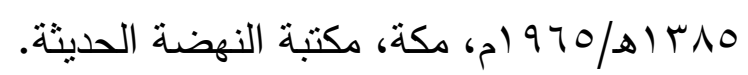

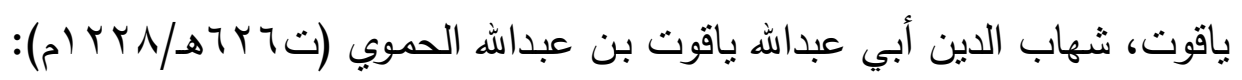

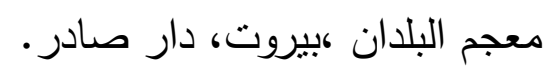


2

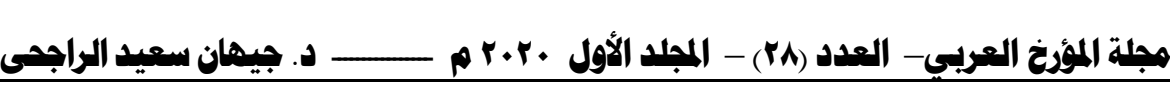

\section{: المراجــ}

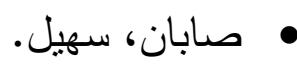

موسـوعي للمصـطلحات العثمانيـة التاريخيـة، طا ، الريـاض، مكتبـة الملـك فهـ

$$
\begin{aligned}
& \text { الوطنية، rاء اهـ/ . . . rم، ص •r . . } \\
& \text { عاشور، سعيد عبد الفتاح. }
\end{aligned}
$$

المجتمع المصري عصر المماليك، القاهرة، مكتبة النهضة، بالهو 9 ام.

الطرابلسي، برهان الدين

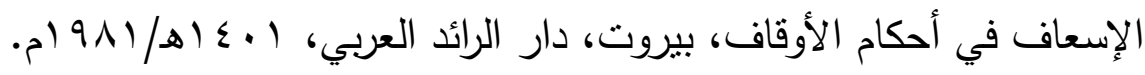

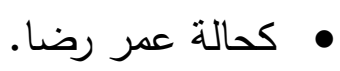

• اعلام النساء في عالمي العرب والإسلام بيروت، مؤسسة الرسالة .

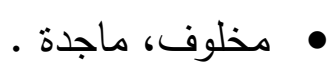

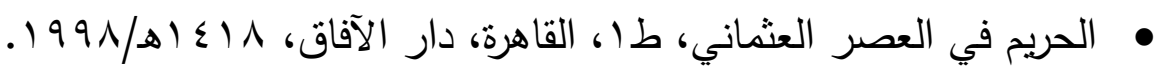
• الخدمات والمرافـق العامـة في مكـة المكرمسة في العهد العثـــي، مـؤتمر مكـة

عاصمة الثقافة، جب أهـ

$$
\text { • • مداح، أميرة بنت علي مداح. }
$$

• أوقاف النسـاء في مكة المكرمة في العصر العثماني ودور المرأة فيها، القاهرة،

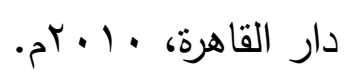

• خيرات مـاه بيكر كوسام والدة السلطان ووقفيتها لخدمة الحرمين الثريفين صورة للتضـامن الاجتماعي، والديني خـال العصر العثماني، المؤرخ المصري، عء ب،

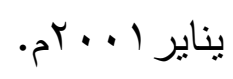

